\title{
CLINICAL AND PATHOLOGICAL PRESENTATIONS OF BRONCHOGENIC CARCINOMA IN A TERTIARY CARE CENTRE
}

\author{
Vishwanath V. Pujari1 ${ }^{1}$ Rahul M. Lokhande2, Sushant H. Meshram³, Rakesh D. Waghmare ${ }^{4}$ \\ ${ }_{1}^{1}$ Assistant Professor, Department of Pulmonary Medicine, B. J. Government Medical College, Pune. \\ ${ }^{2}$ Associate Professor, Department of Pulmonary Medicine, B. J. Government Medical College, Pune. \\ 3 Professor, Department of Pulmonary Medicine, B. J. Government Medical College, Pune. \\ ${ }_{4}^{4}$ Assistant Professor, Department of Pulmonary Medicine, B. J. Government Medical College, Pune.
}

\section{ABSTRACT}

\section{BACKGROUND}

Lung cancer is presently the most common malignant disease (13\% of all cancers) and the leading cause of cancer deaths (19\% of all cancer deaths) in the world in all age groups and in both sexes. It is the leading cause of cancer deaths in developed as well as in developing countries.

\section{OBJECTIVE}

The present study was conducted to study the various clinical and pathological presentations of bronchogenic carcinoma.

\section{MATERIALS AND METHODS}

A total of 82 patients with histologically proven bronchogenic carcinoma, hospitalized between 2012 and 2014 at a tertiary care centre, Pune, India, were analysed.

\section{RESULT}

Out of a total of 82 diagnosed cases, average age was 61 years, nearly $80.0 \%$ were males. Smoking was the risk factor in $63.41 \%$. About $2 \%$ of female patients were smokers. Six (7.3\%) patients were $<40$ years of age at the time of diagnosis. Fiberoptic bronchoscopy (75.60\%) was found to be the most efficient diagnostic procedure. Histologically, adenocarcinoma, squamous cell carcinoma, non-small cell carcinoma and small cell carcinoma were seen in 57.31\%, 24.39\%, 9.75\% and 6.09\% cases, respectively. Distant metastases to organs like nodes, liver, adrenals and bones were present in $67 \%$.

\section{CONCLUSION}

This study shows that adenocarcinoma is the most common type of lung cancer and clinical and radiological suspicion should lead to the prompt diagnosis and management.

\section{KEYWORDS}

Bronchogenic Carcinoma, Bronchoscopy, Adenocarcinoma, Clinical and Pathological.

HOW TO CITE THIS ARTICLE: Pujari VV, Lokhande RM, Meshram SH, et al. Clinical and pathological presentations of bronchogenic carcinoma in a tertiary care centre. J. Evolution Med. Dent. Sci. 2016;5(47):2968-2971, DOI: 10.14260/jemds/2016/692

\section{INTRODUCTION}

Lung cancer is presently the most common malignant disease (13\% of all cancers) and the leading cause of cancer deaths (19\% of all cancer deaths) in the world. ${ }^{1}$ Its incidence peaks between age 55 and 65 years. The age adjusted death rate is decreasing in males and females. ${ }^{2}$ Globally, $85 \%$ of lung cancer in male and $46 \%$ in the female is due to smoking. ${ }^{3}$ Approximately, $10 \%$ of lung cancer patients are asymptomatic at presentation. However, most are symptomatic and may present with non-specific symptoms such as weight loss or fatigue or with direct signs and symptoms caused by the primary tumour or intrathoracic or extrathoracic spread. For the therapeutic decision, lung cancer is categorized as small cell carcinoma or non-small cell (NSC) carcinoma. The major histological classes of NSC carcinoma are adenocarcinoma, squamous cell carcinoma and large cell carcinoma.

Financial or Other, Competing Interest: None.

Submission 14-05-2016, Peer Review 25-05-2016,

Acceptance 27-05-2016, Published 11-06-2016.

Corresponding Author:

Dr. Vishwanath V. Pujari,

Flat No. 3, Riddhi Siddhi Apartment

Opp. Vidyaniketan High School,

Canara Bank Lane, Bibwewadi,

Pune-411037, Maharashtra.

E-mail: vishwapujari11@yahoo.com

DOI: $10.14260 /$ jemds $/ 2016 / 692$
In India, an increased incidence of bronchogenic carcinoma was recognized in the early 1960s by Viswanathan et al. ${ }^{4}$ Subsequently, there have been many sporadic reports on the clinical and pathological features of lung cancer from different parts of the country. ${ }^{5}$ According to National Cancer Registry (2001-2004) of the Indian Council of Medical Research, carcinoma lung constitutes $7.6-11.10 \%$ of all cancers in men and $1.40-2.98 \%$ of all cancers in women in India. ${ }^{6}$ Hospital based data have also shown a similar variability regarding risk factors, clinical presentations, radiological findings and histological diagnosis.

The present study was conducted to document the clinicpathological features of patients hospitalized with carcinoma lung to our centre. This study was carried out to observe the age distribution, sex distribution, clinical and radiological presentation, smoking and histological patterns of carcinoma lung presented to our tertiary care centre over the period of two years.

\section{MATERIALS AND METHODS}

Study population and duration: All patients admitted under the Department of Pulmonary Medicine, in our Tertiary Care Centre at Pune during the specified period. Duration of the study period between 2012 and 2014. 


\section{METHODOLOGY}

Our study included all the consecutive histopathologically proven cases of bronchogenic carcinoma, those either presented first time to our institute or were referred for confirmation of their diagnosis and to receive treatment. Detailed history was taken into an account and smoking habits and exposure were noted including the Radiological presentations.

Type of Study: Observational study.

\section{Aims and Objectives}

1. To study the various clinical, radiological and histological presentations of bronchogenic carcinoma.

2. To study the diagnostic yields of various diagnostic procedures.

3. To study the risk factors for bronchogenic carcinoma.

\section{Inclusion Criteria}

All the patients with histologically proven bronchogenic carcinoma.

\section{Exclusion Criteria}

Intrathoracic masses other than bronchogenic carcinoma. The patients were classified according to the major histologic groups: Adenocarcinoma, Squamous cell carcinoma, Small cell carcinoma, undifferentiated non-small cell carcinoma and others. Immunohistochemistry was not done due to its unavailability at our institute. The data thus collected was analysed using SPSS Software, Version No. 22 and Microsoft Excel 2013.

\section{RESULTS AND OBSERVATIONS}

\section{Clinical Presentation}

A total of 82 cases of lung cancer were diagnosed in our hospital during the period of two years. Of which 80 (97.5\%) patients were symptomatic at the time of presentation and two were diagnosed as an incidental radiological finding. Table 1 shows that Cough was the most common symptom (90.24\%) followed by dyspnoea, probably due to COPD. Haemoptysis was the presenting symptom in 22 (26.82\%).

\begin{tabular}{|c|c|c|}
\hline Sl. No. & Symptoms and Signs & No. of Patients (\%) \\
\hline 1 & Cough & $74(90.24 \%)$ \\
\hline 2 & Haemoptysis & $22(26.82 \%)$ \\
\hline 3 & Chest pain & $21(25.60 \%)$ \\
\hline 4 & Dyspnoea & $34(41.46 \%)$ \\
\hline 5 & Weight loss & $47(57.31 \%)$ \\
\hline 6 & Peripheral & $17(20.73 \%)$ \\
\hline 7 & Lymphadenopathy & $4(4.87 \%)$ \\
\hline \multicolumn{3}{|c|}{ Bable 1: Signs and Symptoms } \\
\hline
\end{tabular}

Radiological Presentations of Bronchogenic Carcinoma

Table 2 demonstrates the different radiological patterns with which bronchogenic carcinoma presented. It includes both CT and Roentgenologic patterns.

The most common radiological presentation was that of a well-defined mass in $63.41 \%$, followed by collapse in $32.92 \%$. Solitary Pulmonary Nodule (SPN) was presenting finding in $3.65 \%$ only.

\begin{tabular}{|c|c|c|}
\hline Sl. No. & Radiological Signs & No. of Patients (\%) \\
\hline 1 & Well-defined mass & $52(63.41 \%)$ \\
\hline 2 & Lobar collapse & $27(32.92 \%)$ \\
\hline 3 & Pleural effusion & $25(30.48 \%)$ \\
\hline 4 & Thoracic metastases & $19(23.17 \%)$ \\
\hline 5 & Extrathoracic metastasis & $23(28.04 \%)$ \\
\hline 6 & Lymphangitis & $14(17.07 \%)$ \\
\hline 7 & SPN & $3(3.65 \%)$ \\
\hline \multicolumn{3}{|c|}{ Table 2: Radiological Presentations } \\
\hline
\end{tabular}

Age and Gender Distribution of the Cases

The youngest patient was 32 years old male and the oldest was 82 years with an average age of 61 years. Out of a total of 82 patients, 66 were males $(80.48 \%)$ and 16 were females $(19.52 \%)$. The ratio of men to women in this group was 4.12:1. Age and sex distribution is shown in Figure 1. In the age group of 20-40 years, all the six diagnosed cases were males. In the age group of 41 to 60 years total 40 (30 males and 10 females) and in the age group more than 60 years 36 patients (30 males and 6 females) had bronchogenic carcinoma.

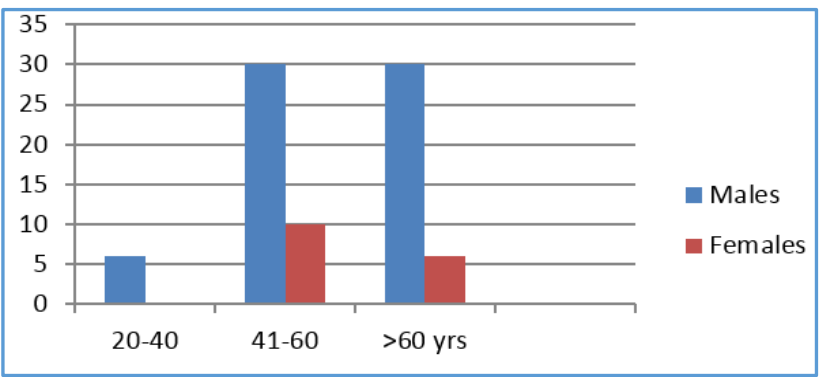

Fig. 1: Age and Gender Distribution

\section{Risk Factors}

Among all the patients, 52 (63.41\%) were smokers; 50 out of the 66 males $(75.75 \%)$ and 2 out of the 16 females $(12.5 \%)$ had a history of smoking. History of tuberculosis was present in $4(4.87 \%)$ patients and $16(19.51 \%)$ patients were on the anti-tuberculosis treatment at the time of diagnosis. These patients were diagnosed on the basis of radiological findings. Two patients $(2.43 \%)$ had a suspected occupational asbestos exposure, but were smokers too.

\section{Diagnostic Yield of Different Diagnostic Procedures}

Table 3 shows diagnostic yields of different diagnostic procedures like Bronchoscopy, pleural fluid analysis, CT guided biopsies and FNAC from peripheral metastatic lesions like lymph nodes. Among the different procedures, Bronchoscopy was the most efficient procedure in the diagnosis of bronchogenic carcinoma $(75.60 \%)$ followed by the others. Of the 20 patients not diagnosed by the bronchoscopy, 10 patients were diagnosed exclusively by pleural fluid cytology, eight were diagnosed by CT guided biopsy and two were diagnosed exclusively by lymph node FNAC.

\begin{tabular}{|c|c|c|}
\hline Sl. No. & Procedure & Yield (\%) \\
\hline 1 & Bronchoscopy & $62(75.60 \%)$ \\
\hline 2 & Pleural fluid cytology & $19(23.17 \%)$ \\
\hline 3 & CT guided biopsy & $8(9.75 \%)$ \\
\hline 4 & Peripheral metastasis FNAC & $15(18.29 \%)$ \\
\hline \multicolumn{3}{|c|}{ Table 3: Diagnostic Yield of Different } \\
Diagnostic Procedures \\
\hline \multirow{2}{|c|}{}
\end{tabular}


Gender Distribution of Cases as per the Histological Type Among the histological subtypes adenocarcinoma was diagnosed in 47 cases (57.31\%), 20 cases (24.39\%) were diagnosed as squamous cell carcinoma, small cell carcinoma in $5(6.09 \%)$, whereas $8(9.75 \%)$ cases could not be diagnosed by histopathology alone and were labelled as non-small cell carcinoma and two were diagnosed as others (Large cell carcinoma-1 and Pleomorphic carcinoma-1). Figure 2 shows the distribution of histological types in our study.

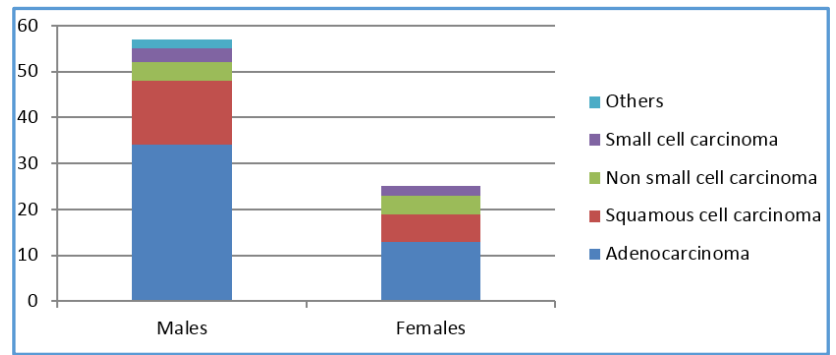

Fig. 2: Gender Distribution of Bronchogenic Carcinoma as per the Histological Type

\section{DISCUSSION}

Bronchogenic carcinoma remains the leading cause of cancerrelated mortality in the developed world and its incidence is rising in developing countries. In this study, we have explored the clinical and radiological profile and histological patterns of bronchogenic carcinoma in patients presenting to our centre. In the present study, cough was the most common presenting symptom followed by dyspnoea, whereas haemoptysis was present in $26.82 \%$ cases. In a study done by Gupta et $\mathrm{al}^{7}{ }^{7}$ found in a retrospective study undertaken in a teaching hospital, weight loss (77\%) and fever (34\%) were the most common general symptoms. Other chest symptoms include cough $(68 \%)$, dyspnoea $(59 \%)$, chest pain $(22 \%)$, haemoptysis $(20 \%)$ and dysphagia $(6 \%)$.

In our study, the most common radiological presentation of bronchogenic carcinoma was a well-defined mass in $63.41 \%$ followed by signs of collapse in $32.92 \%$ cases, whereas Solitary Pulmonary Nodule was a presenting finding in $3.65 \%$ cases. In a study done by Gupta et al, ${ }^{7}$ radiologically obstructive pneumonitis was the most common presentation (59.5\%) followed by mass lesion (31.8\%) and rib destruction (5.1\%).

In a study conducted by Shetty et al, ${ }^{8}$ Solitary Pulmonary Nodule was the most common presenting findings followed by a central lesion and then by a peripheral mass lesion.

In the present study the average age of presentation was 61 years, whereas a youngest case was 32 years old; $48 \%$ patients were in the age group of 41 to 60 years' age group. Almost $80 \%$ were males. Smoking was the most common risk factor for bronchogenic carcinoma; among males 75.75\% cases were tobacco smokers and only $12.5 \%$ female cases were smokers. The National Cancer Database (1996) in the USA reported that the age group most commonly affected was 70-79 years. ${ }^{9}$ The younger age range of Indian patients is similar to that observed approximately 40-50 years ago in developed countries.10 The average age of bronchogenic carcinoma patients was 57 years, which is quite similar to that reported in other Indian studies. ${ }^{11}$ The maximum incidence was found between 50 and 59 years in men and between 40 and 49 years in women. Nine and a half percent of patients were $<40$ years old. Smoking was the most common risk factor associated with bronchogenic carcinoma present in $63.41 \%$ cases, whereas $4.87 \%$ had a previous history of tuberculosis and $19.51 \%$ patients were misdiagnosed as tuberculosis and on the treatment for the same at the time of diagnosis. In the study conducted by Sundaram et al,12 they found nearly $22 \%$ patients were initially prescribed anti-tuberculosis treatment. In a study conducted by S. K. Jindal et al, ${ }^{13}$ for tobacco smoking in India they found that among 37682 males 10756 (28.5\%) were ever smokers and among 35923 females 740 (2.1\%) were ever smokers.

In a study done by Gupta et $\mathrm{al}, 7$ smoking was the risk factor in $81.6 \%$ and nearly $40 \%$ of female patients were smokers with a significant overlap in use of smoking objects, whereas in our study only $12.5 \%$ females were smokers.

In present study, bronchoscopy was the most efficient investigation (Diagnostic yield $75.60 \%$ ), whereas pleural fluid cytology could diagnose $23.17 \%$ cases and $12.20 \%$ cases could be diagnosed exclusively by pleural fluid cytology. CT guided biopsy had 100\% yield and could diagnose $9.75 \%$ cases. In a study done by Gupta et al, ${ }^{7}$ in a retrospective study undertaken in a teaching hospital, fiberoptic bronchoscopy (75\%) and fine-needle aspiration cytology (74.8\%) were found to be the most efficient diagnostic procedures.

In our study adenocarcinoma was the most common histopathological diagnosis (57.31\%), followed by squamous cell carcinoma (24.39\%) followed by undifferentiated nonsmall cell carcinoma (9.75\%), whereas small cell carcinoma was diagnosed in $6.09 \%$ cases. Pleomorphic carcinoma and large cell carcinoma were diagnosed in one case each.

In a study conducted by Yosri M. Aklet al, ${ }^{14}$ four types of bronchogenic carcinoma were found; squamous cell carcinoma $37.4 \%$, adenocarcinoma $29.5 \%$, small cell carcinoma $14.9 \%$, large cell carcinoma $7.2 \%$ and undifferentiated carcinoma $11.1 \%$; whereas in a study done by Sundaram et al, ${ }^{12}$ they found squamous cell carcinoma, adenocarcinoma, small cell carcinoma and large cell carcinoma were seen in $31.67 \%, 43.33 \%, 10 \%$ and $3.24 \%$ cases, respectively; $11.67 \%$ patients showed malignant cells only and marked as unclassified.

\section{CONCLUSION}

In this study adenocarcinoma was found to be the most common type of lung cancer. Bronchoscopy is the most effective diagnostic investigation. Smoking is the most common risk factor, more in males.

This study shows that patients who have persistent clinical and radiological signs of pulmonary disease and a history of smoking must be thoroughly investigated considering the possibility of lung cancer.

\section{ACKNOWLEDGEMENT}

1. Department of Pathology, B.J.G.M.C, Pune.

2. Department of Radiodiagnosis, B.J.G.M.C, Pune.

\section{REFERENCES}

1. Stewart BW, Kleihues P. World cancer report. Lyon: IARC Press 2003;p 265-9.

2. Minna JD. Neoplasms of the lung. In: Kasper L, Braunwald E, Fauci S, et al. (editors) Harrison's principles of internal medicine. New York: McGraw-Hill $2005 ; 16^{\text {th }}$ ed(2):506-7. 
3. Muir CS, Waterhouse JAH, Mack TM, et al. eds, Cancer incidence in five continents. (IARC Scientific Publications No. 88), Lyon, International Agency for Research on Cancer 1987;5.

4. Viswanathan R, Gupta S, Iyer P. Incidence of primary lung cancer in India. Thorax 1962;17(1):73-6.

5. Nagrath SP, Hazra DK, Lahiri B, et al. Primary carcinoma of lung: clinicopathological study of 35 cases. Indian J Chest Dis 1970;12:15-24.

6. National cancer registry. Indian council of medical research, consolidated report of the PBCRs: 2001-2004.

7. Gupta RC, Purohit SD, Sharma MP, et al. Primary bronchogenic carcinoma : clinical profile of 279 cases from mid west Rajasthan. Indian Chest Allied Sciences 1998;40(2):109-16.

8. Shetty C, Lakhkar B, Gangadhar V, et al. Changing pattern of bronchogenic carcinoma : a statistical variation or a reality? Indian Journal of Radiology and Imaging 2005;15(2):233-8.
9. Fry W, Menck H, Winchester D. The national cancer data base report on lung cancer. Cancer 1996;77(9):1947-55.

10. Jindal S, Malik S, Dhand R, et al. Bronchogenic carcinoma in northern India. Thorax 1982;37(5):343-7.

11. Rajasekaran S, Manickam TG, Vasanthan PJ, et al. Pattern of primary lung cancer- a madras study. Lung India 1993;11(2):7-11.

12. Sundaram V, Sanyal N. Clinicopathological profile of bronchogenic carcinoma in a tertiary care hospital in eastern part of India. Clin Cancer Investig J 2014;3(3):220-4.

13. Jindal SK, Aggarwal AN, Chaudhry K, et al. Tobacco smoking in India: prevalence, quit-rates and respiratory morbidity. Indian J Chest Dis Allied Sci 2006;48:37-42.

14. Akl Y, Emam R, Sabry I, et al. Clinico-pathological profile of bronchogenic carcinoma cases presented to chest department, Cairo university in the last 10 years. Egyptian Journal of Chest Diseases and Tuberculosis 2013;62(4):705-712. 